\title{
On Exploitation Situation and Countermeasures Advice in the Development of Tight Gas in China
}

\author{
Wei Li, Yan Shi \\ College of Economics and Management, \\ Northeast Dianli University, \\ Jilin, China
}

\author{
Chunli Song \\ Economic and Technological Cooperation Department of \\ Jilin Province, \\ Changchun, China
}

\begin{abstract}
Tight gas, along with shale gas and coalbed methane, is known as top three unconventional gases. Tight gas development has strategically importance in the development of natural gas and energy structure adjustment in China. It should be considered in priority in the exploration and exploitation of unconventional gas. There are there key factors to develop tight gas: reliable data resources, mature technology, and overlapping with conventional natural gas. Making national development strategy, accelerating the progress of technology, deepening the reform of natural gas price and innovating regulatory system would speed development of tight gas. In future, tight gas will become the main growth of natural gas production.
\end{abstract}

Keywords-tight gas; natural gas; countermeasures

\section{INTRODUCTION}

Tight gas, also known as gas in tight sand, is the natural gas in sandstone formation with permeability less than 0.1 md. Tight gas has very low or none natural production capability, therefore, their mining value has to be revealed by special operations. Tight gas, along with shale gas and coalbed methane, is known as top three unconventional gases. In the tree gases, tight gas takes a considerable proportion. Nowadays, the United States, followed by China, is the most successful country in mining tight gas ${ }^{[1]}$. The large scale exploitation and utilization. of tight gas in the United States has push forward the development of tight gas in China, which has strategically importance in the development of natural gas and energy structure adjustment in China. Coal consumption has taken the leading proportion in the energy structure. In 2011, China has consumed $3.57 b i l l i o n$ ton of coal and 11.85 billion $\mathrm{m}^{3}$ of natural gas, with a proportion of $72.8 \%$ and $4.5 \%$, respectively in the total consumption of primary energy. In face of energy shortage all around the world, we have to change the energy consumption structure by reducing the proportion of coal in the total consumption of primary energy and increasing the proportion of clean energy such as oil and natural gas. According to related data released in 2010, the reserve of conventional and unconventional natural gas in China is 5.2 trillion $\mathrm{m}^{3}$ and 28.06 trillion $\mathrm{m}^{3}$ respectively (Figure 1 ). The unconventional gas is 5.4 times more than the conventional one. As the main part of unconventional gas, tight gas should be developed in the first place.

\section{THE DEVELOPMENT SITUATION OF TIGHT GAS IN CHINA}

Tight gas distributes broadly in China, with its main distribution areas in Erdos, Sichuan province, Tarim Basin, Jungar Basin, and Songliao Basin. The favorable area is $320,000 \mathrm{~km}^{2}$, and reserve takes $90 \%$ of known total exploitation $^{[2]}$. The development of tight gas has reached a certain scale, with the production volume of 2.56 billion $\mathrm{m}^{3}$ in 2011 , which is $1 / 4$ of the total production of natural gas of the year. In 2012, the number is 3.0 billion, taking up merely $1 / 3$ of the total production. According to the prediction by authority, the number will rise to 10 billion by $2030^{[3]}$. The numbers show that tight gas has developed sharply. Tight gas will play a leading role in the development of unconventional natural gas in China. As far as we know, the reserve of tight gas is rich and has actually development value. We should push forward the development of tight gas at present stage.

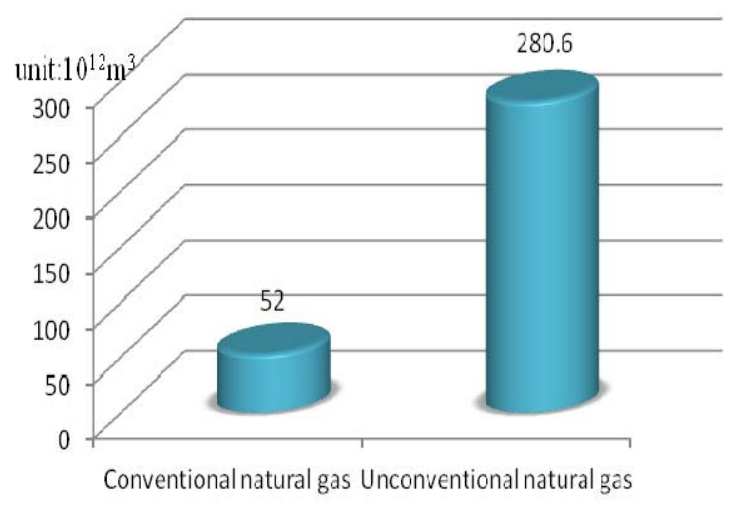

Figure 1. Conventional and unconventional natural gas resources comparison in China.

\section{KEY FACTORS TO DEVELOP TIGHT GAS}

\section{A. Reliable data resources and huge potential}

According to a preliminary estimate by analogy, the technological mining volume of tight gas in China is 1.2 trillion $\mathrm{m}^{3}$, which will continually increase with further exploitation $^{[4,5]}$. Besides, the total explored rate is $18 \%$ of the technological mining volume ${ }^{[6]}$. In other words, tight gas resources have not reached to a comprehensive exploitation stage, if given more attention, the potential will be enormous. 


\section{B. Mature technology and rich experience}

China has explored tight gas since 1970s. With the three stages of start-up, discovery and development, China has overcome major technological difficulties up to now. Supporting technology has come into scale and exploitation technologies such as straight-hole, cluster well and horizontal well staged fracturing have made considerable progress. With the bases of technologies and 30-year-of-experence, developing tight gas in large scale is no more difficult.

\section{Overlapping with conventional natural gas leads to low exploitation cost}

In terms of distribution, tight gas overlaps with conventional natural gas in many areas. In this condition, the infrastructures such as tube and transportation built for conventional natural gas exploitation could be used for the exploitation of tight gas. Thus the cost will be significantly reduced and the economic benefit will increase accordingly.

\section{ADVICES ON DEVELOPMENT OF TIGHT GAS}

\section{A. Make national development strategy, favorable policy and support fund}

The mismatch between development cost and gas price has retarded the large-scale development of tight gas in China. Nowadays, the economic benefit of tight gas is very poor under the acting gas price system; some areas even meet with loss. Therefore, we should make favorable policies and support fund for tight gas development at the same time of technology research. At present, the subsidy to shale gas and coal bed gas is $0.4 \mathrm{RMB} / \mathrm{m}^{3}$ and $0.2 \mathrm{RMB} / \mathrm{m}^{3}$ respectively. As for tight gas, there is no such subsidy, which has reduced the economic benefit of the exploitation and discouraged the explorers. To guide and encourage the development of tight gas, China should issue favorable policies such as tax subsidy, income tax reducing, tax deducted by primary research cost and duty free for imported equipments. Besides, we should release a mid-long term plan for Tight gas as soon as possible, to define the strategic status of tight gas in the national natural gas development and to reduce the gas extra dependence by taking it as energy safety protector.

\section{B. Accelerate the progress of technology and formulate an innovative system}

With more understanding to the geology and tight gas, the development technology has become more advanced. However, compared with those of other countries, we still have a lot to do. The exploitation technology is the base for tight gas development. At present, we mainly adopt optimization in rich areas technology, wells location preference technology, multi-level sand fracturing technology, horizontal wells exploitation as a whole and drainage for gas technology. We should accelerate the research work for better technology to increase the well yield and economic benefit. In accordance with the rapid development of tight gas, we should select typical test area for spot research, focus on development mechanism and law, optimization of well type and network and other support technologies.
Besides, we should enhance self-renovation capability in development technology to reduce cost. Last but not least, we should cooperate with universities and research institutions for cultivation of excellent technology talents.

\section{Deepen the reform of natural gas price; gradually form market pricing mechanism}

China and Russia signed a 30-year natural gas purchase and sale contract, at May 21, 2014, which values a total of $\$ 400$ billion. Though the contract is of great significance to adjust energy consumption structure in China, also it still brings the new challenge to some extent. China natural gas imports were $530 \times 10^{8} \mathrm{~m}^{3}$ in 2013 , an increase of $5 \%$ over the previous year. China natural gas consumption in 2013 reached $1676 \times 10^{8} \mathrm{~m}^{3}$, energy dependency breaks up $30 \%$ for the first time, up to $31.6 \%$. This means when the LNG supply contract comes into effect, the dependency to foreign energy in China will be more serious. In addition, on the whole, the contract will push up the price of natural gas in China, presents the natural gas price to hang upside down phenomenon. Therefore, the unreasonable price relationship between natural gas and other energy needs to be rationalized urgently, push forward natural gas tiered pricing mechanism in a gradual way, form mechanism of experience by the state in a unified pricing gradually to market demand and supply, bring the price of China's natural gas more in line with international practice as soon as possible.

\section{Innovate regulatory system and strengthen talent devel- opment}

Concerning the particularity of tight gas exploitation in China, government policymaking and regulatory functions should be separated from each other and a unified regulatory body should be established as quickly as possible. We should introduce complete regulatory standards, regulatory norms and punitive measures to supervise tight gas exploration and exploitation activities, such as market entry/exit and price regulation and settings, develop multi-levels of the regulatory system including self-regulation, market supervision and environmental regulation which fit nicely with the development of tight gas resource. Meanwhile we should emphasize the importance of public supervision. Strengthening the construction of supervision team and the training of personnel ability is also important. What's more, each well should be effectively supervised by talents who are equipped with comprehensive quality and professional technical knowledge and ability.

\section{THE SIGNIFICANCE OF TIGHT GAS DEVELOPMENT}

In China, the development and utilization of coalbed methane and shale gas is just beginning in unconventional natural gas, it is still a long way to become large-scale and commercialization development. The goal of tight gas development in China is to grow up seven times in annual production by the year of 2030. Compared to the shale gas and coalbed gas, tight gas should be considered in priority in the exploration and exploitation of unconventional gas in China. The large-scale development of tight gas is more realistic, and has gradually become the main growth of 
natural gas production. Tight gas exploitation will be even more practical significance and profitability in the future and will be further developed. Accelerating the pace of tight gas development will not only contribute much to our energy security, promote energy consumption structure adjustment, but can also become an important means to reduce the foreign energy dependency. What's more, from the perspective of reducing carbon dioxide emissions, it will also make great contribution to environmental protection.

\section{REFERENCES}

[1] J. Dai, Y. Ni, X. Wu, Tight gas in China and its significance in exploration and exploitation [J]. Petroleum Exploration and Development, 39(3), pp. 277-284, 2012.
[2] M. Xinhua, J. Ailin, T. Jian, et al., Tight sand gas development technologies and practices in China [J]. Petroleum Exploration and Development, 39(5), pp. 572-579, 2012.

[3] R.L. Kennedy, W.N. Knecht, D.T. Georgi, Comparisons and contrasts of shale gas and tight gas developments North American experience and trends [C]//SPE Saudi Arabia Section Technical Symposium and Exhibition. Society of Petroleum Engineers, 2012.

[4] Y. Kang, P. Luo, Current status and prospect of key techniques for exploration and production of tight sandstone gas reservoirs in China [J]. Petroleum Exploration and Development, 34(2), p. 239, 2007.

[5] G.C. Naik, Tight gas reservoirs - An unconventional natural energy source for the future [J]. www.sublette-se.org/files/tight_gas.pdf. (Accessed on 2003), 1(07), 2008.

[6] Q. Zhongjian, D. Songtao, Strategic position of unconventional natural gas resources in China [J]. Natural Gas Industry, 1, 002, 2012. 